\title{
Digital Knowledge Sharing: Forging Partnerships between Scholars, Archives, and Indigenous Communities
}

\author{
Timothy B. Powell
}

Abstract: The article reviews a digital repatriation project carried out by the Center for Native American and Indigenous Research at the American Philosophical Society over the course of eight years (2008-present). The project focused on building digital archives in four indigenous communities: Eastern Band of Cherokee Indians, Penobscot Nation, Tuscarora Nation, and Ojibwe communities in both the United States and Canada. The article features insights from traditional knowledge keepers who helped to create a new system of costewarding the APS' indigenous archival materials and recounts how the APS established protocols for cultural sensitivity. A new model of community-based scholarship is proposed to create a more equal and respectful relationship between indigenous communities, scholars, and archives.

[Keywords: History of Archives; Digital Repatriation; Digital Knowledge Sharing; Community-Based Scholarship; Cherokee; Tuscarora; Penobscot; Anishinnaabe; Ojibwe. Keywords in italics are derived from the American Folklore Society Ethnographic Thesaurus, a standard nomenclature for the ethnographic disciplines.]

We are living in a remarkable historical moment when the combination of digital technology and cultural revitalization movements in Indian Country have created an unprecedented opportunity to rethink the stewardship of Native American archival collections. What follows is the story of the American Philosophical Society's (APS) work over the last eight years to establish partnerships with indigenous communities. At the heart of these collaborations lies an exchange between equal partners - the communities where the materials originated and the archive that has preserved them so carefully (Christen 2011; Evers and Toelken 2001; Basso 1996). ${ }^{1}$ To recognize and sustain the enduring importance of this work, the APS created a new Center for Native American and Indigenous Research (CNAIR) in 2014, with myself as the director and Brian Carpenter as the senior archivist. CNAIR recently received a Challenge Grant from the National Endowment for the Humanities to endow the Center to ensure its efforts continue far into the future. The mission of CNAIR is to maintain existing partnerships and to build new ones with the intent of getting digital copies of songs, stories, oral histories, and linguistic materials back to the indigenous community where they were first recorded to strengthen ongoing revitalization movements. Now that the Center is established and we have eight years of work to reflect upon, it seems a fitting moment to look back on how CNAIR's Digital Knowledge Sharing program came into being, to discuss honestly the problems encountered along the way,

\footnotetext{
* This peer-reviewed contribution was accepted for publication in Museum Anthropology Review on November 12 , 2016. The work is licensed under the Creative Commons Attribution 4.0 International License. To view a copy of this license, visit http://creativecommons.org/ licenses/by/4.0/
} 
and to share our stories in the hopes that they will benefit other archives, scholars, and indigenous communities (Powell 2015a, 2015b, 2016).

Whereas repatriation efforts between communities and museums have been well documented, less is known about the sharing of archival documents in digital form, even though it has been going on for at least three decades (Gray 1991; Roy and Christal 2000; Christen 2006; Kelty et al. 2008; Shankar and Hooee 2013; Reddy and Sonneborn 2013). ${ }^{2}$ It should be noted at the outset that the sharing of digitized archival documents, photographs, and audio recordings differs significantly from repatriation under the Native American Graves Protection and Repatriation Act (NAGPRA), collaborations to create museum exhibits, or scholars working in partnership with communities on ethnographic projects. In most cases, for example, communities do not want the "original" - whether it be a fragile paper document or a wax cylinder. Most archival materials tend to be copies of copies, although there are exceptions. ${ }^{3}$ Digital copies take up less physical space and if the format becomes obsolete, the APS incurs the expense of updating the technology and agrees to provide the latest digital format to tribes free of cost. Finally, CNAIR, as a library-based entity, devotes its efforts to making its collections more accessible to communities rather than studying the cultures, therefore maintaining a more neutral stance that helps foster trust. As one of our Kwakwaka'wakw partners told me, "we just want the materials back so that we can interpret them ourselves; we've been studied to death."

Against this backdrop, the APS created the Digital Knowledge Sharing initiative implemented by CNAIR. Funded by two consecutive grants from The Andrew W. Mellon Foundation spanning six years (2008-2014), the APS established partnerships with four indigenous communities: the Eastern Band of Cherokee Indians (EBCI), Anishinaabe (Ojibwe) communities in Canada and the US, the Penobscot Nation, and the Tuscarora Nation. Along with these partnerships and related activities, the grants allowed the APS to digitize its entire Native American audio collection, totaling more than three thousand hours. The funding also established a Native American advisory board that worked for two and a half years to create protocols to protect culturally sensitive materials in the APS' Native American and indigenous collections. The grants also funded a study to follow up on how the newly digitized materials were being used by the communities, which will be detailed below. The next step of the process-how building digital archives in indigenous communities can stimulate community-based scholarship-will also be addressed.

Before describing the partnerships, let me explain what I mean by community-based scholarship. The term was taught to me by Richard Hill, Director of the Deyhahá:ge: Indigenous Knowledge Center at Six Nations Polytechnic in Ontario. It has multiple meanings, which are deeply intertwined. From an academic perspective, community-based scholarship is grounded on the principles of respectful collaboration and produces outcomes that directly benefit the community being studied (Tuhiwai Smith 2004; Kovach 2009; Justice 2006; Atalay 2012). The term "scholars" is used in a provocatively broad sense to include not just academics and their graduate students, but also traditional knowledge keepers, K-12 teachers and curriculum developers, and community members teaching indigenous languages and culture within the community but outside the classroom. When I need to remind myself of the full spectrum of audiences CNAIR serves, I think of the Tuscarora Toddlers - a group of pre-K scholars in a total immersion language nest, taught by dedicated community members, who represent our greatest hope that 
the language and the traditional knowledge it encodes will live on for generations to come. The success of community-based scholarship depends on reimagining the relationship between the academic knowledge systems and the knowledge systems maintained by traditional knowledge keepers and community members who are working to pass the teachings on to the next generation. The goal is to foster a new, sustainable relationship whereby educators in both systems respect the validity of each other's knowledge in order to craft mutually beneficial partnerships to improve the quality of education in both systems (Tierney 1992; Barnhardt and Kawagley 2008; Battiste 2002). ${ }^{4}$

The four partnering communities were selected to represent a cross-section of communities with varying degrees of digital infrastructure. The EBCI have casino revenues that they use to fund the Kituwah Preservation and Education Program, directed by Renissa Walker, which includes redundant servers and a total immersion Cherokee language school. Fond du Lac Tribal and Community College (Ojibwe) recently opened the Ojibwemowining Resource Center, directed by Lyz Jaakola, which houses extensive audio and video collections with a recording studio actively used by the community. The Anishinaabe (Ojibwe) First Nations in the remote regions of northern Canada, on the other hand, have virtually no digital infrastructure other than a broadband connection. The Penobscot Nation's Cultural and Historic Preservation department, directed by James Francis, falls somewhere in between, with no casino revenues to support their digital infrastructure but with a gift for grant-writing to support language and cultural revitalization. Finally, the Tuscarora Nation, as of this writing, has thousands of pages of APSdigitized documents stored on portable hard drives, which are being used in highly imaginative and productive ways within the community. What is important to emphasize is that all of these partnerships produced meaningful outcomes, as well as illustrative problems that had to be overcome along the way. One of the primary goals of this article, then, is to emphasize that indigenous communities have a remarkable facility for using digital technology, regardless of their infrastructure. They also face unique challenges that digital humanities (DH) scholars at centers based in universities rarely need to consider. Part of my argument is, then, that indigenous community-based people need to be recognized as "DH scholars" so that the field and granting agencies better serve the public humanities.

The partnerships had three basic components: (1) a Native American fellowship program that allowed communities to select teams of scholars (often teachers, students, linguists, and elders) to come to the APS to review the materials; all of the tribes chosen as partners had an abundance of materials in the archive; (2) funding to pay for the digitization of materials selected by the Native American fellows (the Tuscarora, for example, digitized more than seven thousand manuscript pages and twenty three hours of recordings); and (3) funding for the project director to travel to the communities to study how the APS materials were being used by the community, to advise on preserving the digital materials, and to inquire whether any of the APS materials were considered by the community to be culturally sensitive. Looking back, the reciprocal value of visiting one another over the course of years and listening to one another with great respect helped to reverse a long history of distrust, detailed below.

It is important to emphasis that this study is not generalizable knowledge. If I give the impression that there is a linear path that can be simply followed, then I have failed to convey the individuality of each successful partnership and the unique problems encountered along the way 
(Clifford 1997). Success, then, is not simply the implementation of a preexisting plan, but putting together a small group of highly imaginative and committed community members, archivists, and scholars with shared goals (Christen 2011; Weiner 1992). In short, it is the people who matter most. What follows is the story of how these partners came together to develop a system for co-stewarding archival collections. In a larger historical context, our indigenous partners helped the American Philosophical Society take an important first step towards decolonizing the archives (O’Neal 2015; Cushman 2013; Smith and Wobst 2005; Tuhiwai Smith 2004).

\section{Decolonizing the Archive}

For the APS, it was fundamentally important to begin the process of partnering with Native communities by first reflecting on the history of its collections of Native American and Indigenous materials, which date back to the early national period and still reflect vestiges of that period's biases. The Society's history of collecting indigenous materials can be broken down into three distinct phases, which I will identify as the Jeffersonian, Boasian, and Digital Knowledge Sharing eras. It is with the greatest humility that I situate the work being done by CNAIR as part of the same historical narrative of Benjamin Franklin, Thomas Jefferson, and Franz Boas. The origin story that follows is not a hagiography of Great Men, however, but rather an honest rendering of the complex legacy CNAIR inherited.

The first phase of the Native American collections began shortly after Benjamin Franklin founded the APS in 1743. The following year, Franklin published a folio edition of the Treaty of Lancaster, which recorded the magnificent oratorical skills of Canasatego, the Onondaga spokesman for the Haudenosaunee (Iroquois Confederacy) (Kalter 2006). Thomas Jefferson is credited with beginning the systematic collection of Native American languages during a time when he served simultaneously as the President of the US (1801-1809) and the American Philosophical Society (1797-1814). Peter Stephen Du Ponceau, an accomplished linguist who served as APS President from 1827-1844, built upon Jefferson's vision and played a vital role in making the APS into one of the leading institutions in the country for the study of Native American languages (Freeman and Smith 1966). As the noted historian of anthropology Regna Darnell has observed, prior to the professionalization of the field at the turn of the twentieth century, the APS was "the central institution for the collection of data about the American Indian" $(1998,11)$.

After sending Lewis and Clark off across the continent with vocabulary lists to be filled out collaboratively by Natives from each indigenous community they encountered, Jefferson succeeded in his vision to make the APS a leader in the documentation and preservation of the continent's indigenous languages. This proud heritage lives on to this day. And yet it is absolutely critical to remember that part of Jefferson's legacy casts a far darker shadow. An early architect of Indian Removal, Jefferson proposed a constitutional amendment during his presidency to move Native people off of their ancestral homelands; a proposal subsequently rejected by Congress (Wallace 1999 274). As early as 1803, Jefferson described his Indian policy to Benjamin Hawkins, his superintendent for Indian affairs, noting "the various ways in which their history may terminate," whether through "incorporating themselves with us" or by "the many casualties which may endanger them while a separate people" (Wallace 1999 223). As 
Anthony F.C. Wallace wrote in Jefferson and the Indians: The Tragic Fate of the First Americans: "Ultimately, in Jefferson's view, the Indian nations would be either civilized and incorporated into mainstream American society or, failing this...'exterminated.' The Jeffersonian vision of the destiny of the Americas had no place for Indians as Indians" (1999, $11)$.

Although the APS was not directly involved in Jefferson's early attempts at Indian Removal, the mentalite of removal continues to shape the cultural contours of the archive. It is interesting to study closely, for example, the story of how Jefferson obtained the first "Indian wordlist" he collected himself. In 1791, Jefferson visited an Unkechaug (known to him as the Unquachog) community on Long Island and documented more than two hundred words in the language. At the bottom of the vocabulary list, Jefferson wrote: "there remain but three persons of this tribe now who can speak its language. These are old women" (Jefferson 1791). Sadly, Jefferson did not see fit to record the names of these women; in neglecting to do so, he removes them from the history preserved by the APS. Looking back, however, one now realizes that it was a meeting of equals, between keepers and collectors of knowledge that both parties valued deeply. Although, to give credit where it is long overdue, the three women knew much more about the Unkechaug language than Jefferson.

Language documentation, during the Jeffersonian era, meant the collected material was removed from the community and housed in Philadelphia, where it has not been readily accessible to speakers of the language for hundreds of years. This sense of loss would become keener as the twentieth century progressed and witnessed endangerment and loss of many indigenous languages (Harrison 2007, 11). As Jefferson wrote, his vision was that indigenous languages would be "deposited in all the public libraries" so that it "would furnish opportunities to those skilled in the languages of the old world to compare them" (Jefferson 1999, 104). This one-way flow of information from the tribe to the library in Philadelphia, with the attendant notion that the primary audience was non-Native scholars, continued to guide APS policy for the next two hundred years. Thus, the origin story of the APS' Native American and Indigenous materials tells both how traditional knowledge was removed from indigenous communities to the archive and how indigenous knowledge keepers were removed from the archival record.

The next significant period of building the Native American collection began in 1945, when Franz Boas and Edward Sapir oversaw the donation of the vast collection of the American Council of Learned Society's Committee on Native American Languages (Freeman and Smith 1966, 9-10). The accession of this remarkably expansive collection - over eighty linear feet and containing at least one hundred sixty-six languages and dialects from the US, Canada, and Mexico - was followed by the donation of Franz Boas' own papers and those of many of his most distinguished students (Lingelbach 1953, 485). Thus, in the middle of the twentieth century, the APS once again rose to prominence as a leading institution for the study of indigenous cultures, this time with a focus on ethnographic as well as linguistic materials. To date this second phase as beginning in 1945 is somewhat misleading, however. Boas began doing fieldwork on the Northwest coast, primarily with the Kwakuitl (or Kwakwaka'wakw, as they are now known) in 1888, so it is more accurate to date the Boasian period to the late nineteenth century. An end date is equally elusive because Boas' pervasive influence continues to live on in the present generation of anthropologists. My intent here is not a formal chronology, but rather a 
demonstration of how CNAIR has been shaped by both the Jeffersonian and Boasian traditions, in both positive and problematic ways.

Unlike Jefferson, the Boasians carefully and respectfully recorded the names of the indigenous wisdom keepers with whom they worked and provided a remarkably detailed record of the cultures they studied (Darnell 2001). The Boasian period is often described as the era of "salvage anthropology," when linguistics and ethnographers believed they were saving indigenous languages before they inevitably disappeared (Trouillot 2003). The "salvage" metaphor does not, however, do justice to the close relationships anthropologists often developed with their "informants," or what we now recognize as traditional knowledge keepers or community-based scholars. Boas, like many of his peers, believed that the Kwakwaka'wakw's traditional culture was at grave risk because of European incursions. And yet whereas Jefferson passively erased the name of the Unkechaug women who shared their language with him, Boas would credit his Kwakwaka'wakw collaborator George Hunt as co-author on his first major monograph, The Social Organization and the Secret Societies of the Kwakiutl Indians (1897). Half a century later, Frank Speck, one of Boas' first students, acknowledged co-authorship of Cherokee Dance and Drama (1951) with Leonard Bloom and the Cherokee traditional knowledge keeper Will West Long. Long, who also worked with James Mooney and Franz Olbrecht, was given the rare honor for an indigenous knowledge keeper of having his obituary published in the American Anthropologist, written by Speck's student John Witthoft $(1948,358)$. These relationships are still well remembered by community members and the return of audio recordings and manuscript materials collected by the Boasians constitutes one of the most important resources for supporting land claims, language preservation, and cultural revitalization projects in the communities of origin. ${ }^{5}$

The third and current phase of the APS' Native American collections, the Digital Knowledge Sharing initiative implemented through CNAIR, strives to help heal the wounds caused by the mentalité of Removal and to build upon the turn from salvage anthropology to more respectful forms of collaborative research (Watkins 2001; Bruchac 2005; Trouillot 2003) without ever forgetting that these policies constitute an ineluctable part of our past. The turning point came shortly after I began working at the APS in 2008 when the Unkechaug Nation contacted the APS requesting that we digitize the Jefferson vocabulary list. Chief Henry Wallace and tribal linguist Howard Treadwell, collaborating with scholars from Stony Brook University, were working to revitalize a language the APS had considered extinct for more than two centuries (Cohen 2010). This encounter with the tribe who collaborated with Jefferson on the foundational document of the APS Native American collections constituted a crucial turning point, for it helped the APS realize that indigenous communities were researchers, not just objects of research. On a more personal level, the Unkechaugs' brilliant use of digital technology to revitalize their language inspired the ideas that would, over the next six years, grow into the Digital Knowledge Sharing initiative. The success of the initiative can be measured by the fact that the APS has sent digital materials to more than one hundred fifty indigenous individuals and communities across North America since the Unkechaug taught us what digital knowledge sharing could mean.

Librarian Martin Levitt deserves a great deal of credit for overseeing this historical turn. During the last years of his long tenure at the APS, before he retired in 2014, the APS devoted considerable resources to implementing the Digital Knowledge Sharing (DKS) era, which 
culminated with the founding of the Center for Native American and Indigenous Research (CNAIR) in 2014. The endowment of the Center ensures that the practice of DKS and partnerships with indigenous communities will live on long after the end of the grants that brought them into being, providing the elusive answer to questions of sustainability. The creation of the Center also marks the beginning of an intensive effort to decolonize the archive and to recognize, at long last, the fundamentally important role played by both present and past Native wisdom keepers, dating back to the three unnamed Unkechaug women who helped establish the APS' world-class collection of Native American archival materials. While we have long recognized the role of the Founding Fathers in the APS' history, perhaps the time has finally come when we can fully acknowledge the Founding Mothers.

\section{Outcomes of Tribal Partnerships}

As many scholars have recently pointed out, traditional indigenous knowledge can be extremely valuable to both Native and non-Native peoples (Grant-Costa, Glazaand, and Sletcher 2012; Christen, 2011; Becvar and Srinivasan 2009; Ginsberg 1994). My goal here is to demonstrate how the Digital Knowledge Sharing initiative has begun the process of merging indigenous and archival knowledge systems. As the traditional knowledge keepers on the advisory board-Tom Belt (Cherokee Nation), Wendy Bissell (Tuscarora Nation), Watie Akins (Penobscot Nation), and Larry Aitken (Leech Lake band of Ojibwe) taught us, the stories and history come alive in the hands of people from the community of origin. ${ }^{6}$ As Larry Aitken explains: "I think what really needs to be said to those people who are in museums or archival centers" is that these objects "may be in a dormant state, but [they're] still alive....And so I want to take back, as an ambassador for our people...that lesson...that [digital technology] can invigorate and enliven and inspire knowledge and wisdom and learning" (Aitken 2007).

And yet, as many museum staff members and anthropologists have discovered, collaborations with indigenous communities can be vexed by tribal politics, the widespread absence or disregard of protocols by archives to protect cultural sensitivities, and misunderstandings about the sustainability of partnerships beyond the end of a grant period. In "The Currency of Consultation and Collaboration" (2008), Ann McMullen offers a refreshingly honest appraisal of how "warm and fuzzy" projects designed to work in partnership with indigenous communities can give way to the contingencies of community expectations, tribal protocols, and conflicting value systems. McMullen recounts the story of her work with Huichol (Wixarika) people on a collaborative project for the National Museum of the American Indian's (NMAI) inaugural Our Peoples: Giving Voice to Our Histories exhibit, a cautionary tale worth quoting at length:

We invited Huichol community members to return to NMAI to consult on their exhibit's organization and design....But when our Huichol friends left their community to travel to the coast, it began to rain and storm; this was so severe that the roads were washed out and they had to return home. Several weeks later, they finally made it to Washington, D.C. and began our discussions by explaining that the storms that had delayed their arrival...signified the anger of the deity Takutsi Nakawe (Grandmother Growth), who controls both benevolent and destructive.... [The NMAI] had to fulfill our debt to her [Nakawe] through the 
sacrifice of a bull so she would stop punishing Huichol lands and people with destructive storms. [McMullen 2008, 59]

McMullen concludes with the lament, "admittedly, we had never worked with the Huichol before, but nothing in the available literature suggested that the appropriate traditional payment for hearing flood narratives was the timely sacrifice of a bull to Nakawe" (McMullen 2008, 59). While I admire McMullen's honesty in addressing the problems that almost always occur in such collaborations, I want to suggest respectfully that the "available literature" is not necessarily the right place to look for answers (Swan and Jordan 2015; Jackson 2000). I take to heart the advice of the Kiowa elders who advised the Sam Noble Museum:

In reflecting on this [exhibit, Ageless We Dance] the elders have suggested that in the future...project coordinators might consider spending more time in the community, visiting with more people... and perhaps even living for some time in the community. [Swan and Jordan 2015, 50]

As Swan and Jordan (2015) point out, anthropologists have practiced this methodology since James Mooney began the practice in the 1880s; for archivists, however, this level of engagement remains a largely unexplored possibility. Further complicating the process, archivists unlike ethnographers typically have no training to prepare them for the spiritual dimensions McMullen's analysis brings forward.

Collaborations inevitably entail difficult and problems, which we should strive to see as part of the process, rather than simply as impediments that did not lead to goals developed before the partnership began (Swan and Jordan 2015). An important step for archivists, as scholars better understand, begins by respecting the value systems of the indigenous communities and appreciating that these cultures have their own sophisticated, fully formed protocols that in many cases must be learned the old fashioned way, by listening carefully to the oral tradition (Clifford 2004; Evers and Toelken 2001). If we are going to be equal partners, then archives must respect indigenous protocols to protect Cherokee sacred formulas in the James Mooney papers or the Pueblo of Isleta paintings in the Elsie Clews Parsons collection, or photographs of Haudenosaunee masks in the William Fenton Papers. In turn, the APS asks tribes to understand our library protocols - that anyone who comes to the archive can see any of materials (unless restricted by white anthropologists at the moment of accession), even if they have been deemed culturally sensitive by the communities. It is a difficult task, but the APS' experience shows that most tribes appreciate simply being asked to co-steward the collections and that this trust helps bridge the gap between the two systems of protocols.

In the following section, I will document what happens when archival documents come back to life in the hands of traditional knowledge keepers by briefly recounting the challenges and final outcomes of the collaborations with our four partnering communities. The analysis will then circle back to explain in more detail the first steps of building a strong relationship with the Eastern Band of Cherokee Indians. My hope is to provide a model for other archives interested in Digital Knowledge Sharing. On a deeper level, I want to document how collaborations with indigenous knowledge keepers fundamentally reshaped APS policy, protocols, and the accessioning of new materials. As Tom Belt, a Cherokee elder explained, "we have kept this knowledge for thousands of years. We appreciate that the APS has done such a good job or 
preserving it and sharing it with us. The time has come now for us to be co-stewards of this knowledge" (Belt 2014).

\section{Anishinaabe First Nations in Canada}

One of the most dramatic examples of how the simple act of digitizing archival materials and integrating them into traditional knowledge systems can have an enormous historical impact is the case of Pimachiowin Aki Corporation. Pimachiowin Aki (Anishinaabe for "The Land that Gives Life") is a partnership between five Ojibwe First Nations in remote central CanadaPauingassi, Pikangikum, Little Grand Rapids, Poplar Hill, and Blood Vein River - the Provincial governments of Manitoba and Ontario, and the Canadian government. ${ }^{7}$ Led by Sophia Rablauskus and Gord Jones, Pimachiowin Aki used more than four hundred photographs from the APS' A. Irving Hallowell collection for a UNESCO World Heritage Site application to preserve more than thirty three thousand square kilometers of boreal forest and the cultural landscape of these First Nations' ancestral homelands . The realization that old photographs from the APS' collection could help preserve Anishinaabe lands for generations to come galvanized the APS administration and its distinguished members (Powell 2015a).

This partnership also revealed the how critically important the reciprocal visits between community members and APS staff were to the success of the Digital Knowledge Sharing initiative. This personal interaction helped to build a newfound trust between the partners that resulted in very tangible benefits for both sides. For example, Maureen Matthews, an anthropologist working for Pimachiowin Aki, who embodies all of the finest qualities of community-based scholarship, donated more than four hundred and fifty hours of oral histories to the APS, in part because of her respect for the APS' commitment to working with the communities. $^{8}$ Maureen worked with Anishinaabe speakers Roger Roulette and Margret Simmons, among others, to record dozens of hours of interviews with descendants of the people depicted in the Hallowell photographs, providing a remarkably rich cultural context for the images. Maureen then worked with community members to document the names of Anishinaabe people in the Hallowell photographs. In 2013, Maureen came to the APS with Pat Ningewance, a highly skilled Ojibwe speaker and writer, to enter the names into the metadata for the APS' new Digital Library. The names are recorded in both English and Ojibwe, thus implementing another major shift in the APS' august history by beginning the process of indigenizing the archive, an outcome that will benefit Native and non-Native researchers alike. ${ }^{9}$

In July of 2016, the month that the Pimachiowin Aki proposal was to be given final consideration by the World Heritage Committee, after three years of revisions, one of the participating First Nations pulled out at the last minute. A fuller explanation of the unpredictability of tribal politics and the scar tissue of historical trauma is beyond the present scope of this study. Suffice it to say, the collaboration between Pimachiowin Aki and the APS provides a painful lesson in the role of the unforeseen in collaborative projects. The effort, which I will hope will eventually succeed, should not be considered a failure. Remarkably, UNESCO reformed its evaluating process after the first submission of the grant because they realized they did not have the necessary criteria to evaluate how traditional Ojibwe knowledge played an 
integral role in the preservation of the boreal forest. As Albert Einstein is reported to have said, "you never fail until you stop trying."

\section{Penobscot Nation}

One of the great joys of building partnerships is the opportunity to spend time, both in the archive and in the community, with traditionally trained elders like Watie Akins of the Penobscot Nation. Unlike other APS grant programs, the Native American Fellowships were designed to welcome groups of elders and community-based researchers working collaboratively with academic scholars. In 2009, Watie Akin came to the APS with the academic linguist Conor Quinn. Watie had worked for many years to get Frank Siebert's Penobscot-English dictionary, housed at the APS, published. Although considered the "most complete documentation of the language in existence," the only extant print copies are a spiral-bound xerox edition published locally by the Penobscot Nation (American Philosophical Society "Frank Siebert Finding Aid"). In 2009, Siebert's dictionary existed as obsolete floppy disks at the APS. Even after the APS converted them to a contemporary digital format, the dictionary was of minimal use because with so few speakers left, most community members could not look up words in the Penobscot language. Conor Quinn then successfully "flipped" the dictionary to English-Penobscot, thus making it much more valuable to the indigenous and academic communities.

It is important to note that the Penobscot harbor mixed feelings for Frank Siebert. Though his work was funded by two Documenting Endangered Languages grants submitted by the Penobscot Nation to the National Science Foundation, Siebert never discussed whether this support gave the Nation a stake in the copyright of the dictionary. As Jane Anderson argues convincingly in "Access and Control of Indigenous Knowledge in Libraries and Archives," US copyright law is notoriously unhelpful regarding indigenous forms of expression like the oral tradition (Anderson 2005, 9-10). In Copyright and Cultural Institutions: Guidelines for Digitization, the authors write:

Federal copyright protection only arises when a work is fixed in a tangible medium of expression....The requirement that a work must exist in tangible form can mean that meritorious subject matter-such as improvised music and dance, extemporaneous speeches, oral stories, and so forth-are ineligible for federal copyright protection because they have never been committed to material form. [Hirtle, Hudson, and Kenyon 2009, 29-30]

Copyright law is, therefore, a discursive place wherein traditional and legal knowledge systems remain far apart. CNAIR is continuing to discuss these issues with Anderson, one of the leading anthropologists studying indigenous copyright, who is working closely with the Penobscot Nation's Intellectual Property Committee (Anderson 2005, 2006, 72-82).

The digital version of the dictionary was presented to James Francis, director of the Penobscot Nation's Cultural and Historic Preservation Department. James wrote two successful grant applications to the Administration for Native Americans (ANA) and the National Endowment for the Humanities and National Science Foundation's Documenting Endangered Languages 
program. The first grant successfully integrated the dictionary into the community and the second will be used to publish the dictionary in collaboration with the Folklife Center at the University of Maine, Orono, directed by Pauleena MacDougle. Led by community members James Francis, Gabe Paul, and Carol Dana (a tribal linguist who worked with Siebert), the Penobscot did an extraordinary job of recording audio files for each of the entries and making them available to every part of the community, from elders in the retirement home, to K-12 teachers, to young people learning about their traditional culture on canoe trips across the tribe's ancestral homelands. Given that the last fluent speaker died in 2006, this partnership has given new hope to the dream that the Penobscot language will be brought back from the brink of extinction and revitalized for the community.

\section{Tuscarora Nation}

The partnership with the Tuscarora Nation demonstrates how digital knowledge sharing can help support young Native scholars whose graduate studies are carefully designed to benefit their communities. In 2008, the Tuscarora sent a team to the APS consisting of elder Wendy Bissell, tribal historian and high school teacher Vince Schiffert, elementary school teacher Joanne Weinholtz, and two younger scholars: Montgomery Hill and Mia McKie. Joanne and Vince taught Mia and Monty when they were in first grade - a vivid reminder of how community-based scholars can help prepare the upcoming generation for college (Monty is at the University of Buffalo and Mia, at the time, was at Cornell University; she is now enrolled in the Indigenous Governance masters program at the University of Victoria). After consulting with elders back home, the tribe decided to send Mia and Monty to the APS for a month, on a fellowship sponsored by the Library, to digitize a work chosen by the Tuscarora: Charles A. Cooke's "Iroquois Personal Names." Cooke, a Mohawk scholar whose traditional name was Thawennensere, spent fifty years collecting traditional names dating back, in some cases, to the seventeenth century (Barbeau 1952, 424). Each entry consists of a linguistic analysis of the name, a brief history of the person who formerly held the name, as well as valuable information such as the tribal and clan affiliations, and where the name was collected. Because Mia and Monty were at the APS for an extended period of time, it gave the CNAIR staff time to listen and to learn what the names meant to many different Haudenosaunee communities across Canada and the US. The collection includes six thousand two hundred names. As Mia explained, they are given out by Clan Mothers according to clan affiliation, making Cooke's alphabetic arrangement of the names difficult to use for those searching through the one thousand three hundred page manuscript. Because the Haudenosaunee are in the midst of a remarkable period of cultural revitalization in which many more people are seeking traditional names, there are not enough names to go around because Haudenosaunee protocols mandate that only one living person can have a specific name at any one time.

Based on these conversations, CNAIR committed to creating a database of the Cooke collection that could be searched by clan or place name, thus making it much more useful to the Clan Mothers authorized to give out the names. Students at Penn and Swarthmore (overseen by Tim Powell and Keat Murray respectively, with Brian Carpenter doing the editing), worked for more than two years to transcribe the names and Cooke's detailed notes, thus providing non-Native 
students far removed from reservations with an important opportunity to do meaningful community-based scholarship.

The problem that arose was how to disseminate the database without any central digital infrastructure shared by the Six Nations of the Haudenosaunee. The IT department APS, with its state of the art digital infrastructure, is going through a time of restructuring and rapid turnover of personnel, leaving the project stranded at the end of a long line. And so our Tuscarora partners Joanne Weinholtz, Mia McKie, Wendy Bissell, Vince Schiffert, and Sue Hill (Mohawk) simply used word of mouth and Facebook (interestingly) to summon the Clan Mothers charged with distributing the traditional names. This left us astonished at the breadth and efficiency of the traditional educational system of Clan Mothers and Faithkeepers, who quickly connected the names recorded in Philadelphia to the upcoming generation much more effectively than the sophisticated digital systems at the APS could have done!

\section{Eastern Band of Cherokee Indians (EBCI)}

The partnership with the EBCI, which will be detailed at greater length below, led to one of the most important outcomes during the three-year grant period (2011-2014) - the creation of archival protocols to protect culturally sensitive materials. Although the EBCI did digitize a significant amount of archival materials for use in their total immersion language school, their first priority in working with the APS was to protect the sacred formulas housed there. T.J. Holland, the Head of the Cultural Internal Review Board for the tribe arranged for six elders and one younger man being trained as a traditional knowledge keeper to come to the APS to look through documents written in the Cherokee syllabary. The elders identified the sacred formulas and helped us to compose a list of select materials that were then restricted from reprography. Because the APS is a library, the compromise we reached is that anyone coming to the library could see any of the items designated as culturally sensitive by the indigenous community of origin, but that these items could not be photographed or otherwise reproduced. T.J. Holland and Tom Belt, a distinguished elder from the Cherokee Nation who works on language preservation with the EBCI, both served on the APS' Native American and Indigenous Advisory Board. The Board is currently headed by Robert J. Miller, a professor at the Sandra Day O'Connor Law School at Arizona State and a member of the Eastern Shawnee Tribe of Oklahoma. Denise Zuni, an Attorney from the Pueblo of Isleta also deserves a great deal of credit for drafting and revising the protocols.

The Native American and Indigenous Advisory Board, working with Librarian Martin Levitt and Associate Librarian Charles Greifenstein, completed work on the "American Philosophical Society Protocols for the Treatment of Indigenous Materials" in 2014, after a herculean threeyear effort (Powell 2015b). It was a landmark achievement among archives, given that the Society of American Archivists still has not adopted protocols after nine years of debate (O'Neal 2014). I cannot emphasize strongly enough how the protocols helped to overcome the historic distrust that has plagued tribal-scholarly-archival relations over the last one hundred years. The protocols constitute an important recognition of the sovereignty of Indigenous Nations, forming an enduring partnership for co-stewarding the collections. The protocols have greatly benefitted the APS because opportunities to interact with highly knowledgeable, authorized tribal 
representatives has helped to correct mistakes and to enhance the descriptive metadata for the Native American materials housed at the Society. It is our greatest hope that this accomplishment will encourage other archives to adopt their own protocols.

\section{Before the Return}

There is some excellent scholarly work being done on what digital technology can mean for indigenous communities. As Joshua Bell, Kimberly Christen, and Mark Turin recently observed in a special edition of Museum Anthropology Review, entitled "After the Return":

the specificity of digital resources - the ease with which they can be copied, distributed, and revised, their ability to exist in multiple locations at once" allows them to be "constituted anew through the collaboration that they (i.e., digital technologies) help to engender. In this way digital returns not only decenter the authority of museums [and archives] but in doing so remind us of the different ontologies in which objects are situated and by which they are understood." [Bell, Christen, and Turin 2013, 5, my brackets]

My hope here is to augment the important work done in "After the Return"- exploring digital capabilities, decentering and re-centering authority, and understanding digital objects within the context of indigenous knowledge systems. Adding to the conversation, I want examining the steps CNAIR took "before the return," which proved to be crucial to the success of the project.

The partnership with the EBCI began as the APS was in the process of digitizing its entire collection of Native American audio, totaling three thousand one hundred fifty two hours, under the auspices of the first Mellon grant (2008-2011). At first, the Cherokee were simply a subject heading in the online catalogue - a search term that calls up, for example, a letter by Benjamin Smith Barton donating materials given to him by "visiting Cherokee Indians" in 1792 or a letter to Benjamin Franklin noting that "a few hints drawn from them [the Cherokee] might have prevented the cruel depredations" of "the Cherokee War" (Smith 1792; Collinson 1763). When the digitization project began, we were not really concerned with identifying nameless "Cherokee visitors" or picking up on Franklin's suggestion that there might be "hints" that could improve relations with Cherokees. Like many archival digitization projects, the original idea was based on the "big data" model: digitizing the APS' large collection of indigenous audio recordings, describing them in greater detail, and then making them available online, with little thought to whether the community might consider them to be culturally sensitive. As Brian Carpenter, now CNAIR's senior archivist, began cataloguing the audio recordings, however, "Cherokee visitors" began to reveal themselves and to share their stories. In archival terms, this shift resulted from cataloguing the collections at the "item level," rather than the "collection level." The valuable information revealed by this more granular level of cataloguing can best be illustrated by comparing the two versions of a recording made by Will West Long with Frank Speck in 1964. Before 2010, the metadata read: 


\begin{tabular}{|c|c|c|}
\hline Entry: & 40864169 & Add \\
\hline & Tribe: & Cherokee (Iroquoian) (Linguistics) \\
\hline & Author: & Speck, Frank G. \\
\hline & Title: & $\begin{array}{l}\text { Recordings of Cherokee, Creek, Naskapi, } \\
\text { Penobscot, Sioux (Santee), Tintelo, and Winnebago }\end{array}$ \\
\hline & Date: & 1964 \\
\hline & Type: & Sound Items \\
\hline & Format: & Recordings \\
\hline & Extent: & 4 reels of tape \\
\hline & Language: & $\begin{array}{l}\text { Cherokee | Creek | Naskapi | Penobscot |Sioux } \\
\text { (Santee) | Tintelo | Ho-Chunk | Winnebago }\end{array}$ \\
\hline & Description: & $\begin{array}{l}\text { Re-recorded from discs made in the } 1930 \text { s. } \\
\text { Originals in possession of the Museum of Primitive } \\
\text { Art, } \\
\text { Sew } \\
\text { See also, Frank G. Speck, "Table of contents to } \\
\text { Record 49," n.d., Miscellaneous Manuscripts (Misc. } \\
\text { Manuscripts). }\end{array}$ \\
\hline & Collection: & $\begin{array}{l}\text { Recordings of Cherokee, Creek, Naskapi, } \\
\text { Penobscot, Sioux (Santee), Tintelo, and Winnebago } \\
\text { (Rec. 49) }\end{array}$ \\
\hline
\end{tabular}

Here, Will West Long's contribution and those of the knowledge keepers from seven other tribes has been erased and Frank Speck is solely credited with being the "author" of these recordings, which are part of "The Frank Speck Papers." The metadata is colonized in the sense that the inherently collaborative effort, which Speck openly acknowledged, is reduced to the name of the white anthropologist who put the needle down on the wax cylinder. The monumentality of the mistake is best comprehended by considering the larger historical context. At the time Speck collected the recording, Cherokee wisdom keepers had maintained traditional stories like this one for centuries, if not millennia, before Speck arrived on the scene. Although the author of such ancient stories can never be known, we do know with certainty that Frank Speck could not have made the recording without the knowledge passed down to Will West Long by generations of what might be thought of as indigenous archivists and scholars.

The revised catalogue description constitutes a small but important step in the larger project to decolonize the archives: 


\begin{tabular}{ll}
\hline Object ID & audio:4983 \\
\hline Identifier(s) & local: APSdigrec_1238, local: 03, local: 06 \\
\hline Title & Story of Long Life and Going to Heaven \\
\hline Contributor & $\begin{array}{l}\text { Speck, Frank Gouldsmith, 1881-1950 } \\
\text { (researcher), West Long, Will (speaker) }\end{array}$ \\
\hline Subject & $\begin{array}{l}\text { Speeches, addresses, etc., Cherokee, } \\
\text { Cherokee language }\end{array}$ \\
\hline Type & Sound, oratory, primary_text \\
\hline Access & $\begin{array}{l}\text { Copyright American Philosophical Society. For } \\
\text { reproduction and permission information, see } \\
\text { Notes }\end{array}$ \\
\end{tabular}

Here the concept of Frank Speck as "author" of the story is re-centered and Speck and Long are co-listed as "Contributors." 10 The designations of Speck as "researcher" and Long as "speaker" also provide an important insight, I think, into the passive and active roles, respectively, in the production of this archival record. At the very least, the metadata reestablishes the fact that the recording of the "Story of Long Life and Going to Heaven" was a collaborative effort and, more importantly to our indigenous partners, the collections can now be searched by the name of the Native person who kept and shared that knowledge. The digitization and cataloguing process of the first Mellon grant thus reverses the mentalité of removal, allowing the Native wisdom keepers to step out of the shadows and begin to speak in their own voices. Because all the newly digitized audio recordings not considered culturally sensitive can be accessed online, these indigenous voices were available to speak directly to their communities. To again give credit long overdue, these voices will not be heard by third graders or elders if it not were for the dedicated work done by community members.

One of the challenges in bringing together archivists and traditional knowledge keepers is the culture gap that quickly emerges between two very distinctive knowledge systems. Most archivists and IT specialists do not learn about Native American culture as part of their formal training. As a Native American studies scholar working within an archive and actively doing fieldwork in partnering communities, my role is to act as a go-between and to facilitate the interaction between these two knowledge systems (i.e., Cherokee traditional knowledge system and the APS' content management system). One of the most effective ways to address this challenge is to approach the collaboration in terms of shared values. Both archives and communities, for example, are deeply invested in preserving knowledge and making it useful to future generations. The Cherokee value system teaches that the measure of one's accomplishments is evaluated by whether they honor those seven generations in the past and benefits those seven generations in the future. Interestingly, it is the same value system (not as poetically stated) that underlies the APS' mission as an archive. Given these shared values forming the foundation of understanding, the next question is the cultural divide between digital 
archivists and traditional knowledge keepers could be bridged by shared metaphors: (1) computer and cultural codes; (2) archival and indigenous protocols; and (3) traditional knowledge and content management systems.

The potential for bridge building became evident by enlisting the help of Tom Belt before the grant proposal was written. Listening to Will West Long's recording of the "Story of Long Life and Going to Heaven," Tom helped us understand how cultural codes and traditional protocols operate both within the recording made in the late 1930s and within the EBCI community today. Understanding the cultural dimensions of these digital recordings, "before the return," proved crucial to establishing the trust and understanding needed to build an enduring partnership. Tom Belt, of course, speaks only for himself but his thoughts are worth considering carefully and at length. "When I first heard" the recording, Tom began,

I was going to listen to it for all of the morphemes and prenominal prefixes and how they conjugated things... because I'm sort of into that kind of thing now [as a linguist teaching at Western Carolina University]. But almost immediately, I switched over and began to listen to it as I would listen to an elder speak....If it can switch tracks for me from...looking at this from a scholarly angle to sort of becoming a child again listening to an elder then that's the effect it has......And even in a recording, disconnected from the actual person, not only by time but by...I mean not just in place but by time and by death itself. It seems to still have the same effect. [Belt 2010]

The first semantic layer Tom identifies is the value of the recording to linguists and scholars, its morphemes and prenominal prefixes (a kind of academic code). Moving deeper, Tom begins to discuss what the story means in a Cherokee cultural setting rather than a scholarly context. Tom points to the "effect" encoded into the story (story here meaning: [1] the intangible heritage passed down though the generations to Will West Long; [2] the voice and cadence of the storyteller; [3] the transcript; and [4] the digital object). The "effect" Tom identifies is the power the story possesses to transform the listener, provided they are a fluent speaker of Cherokee, as Tom is. Tom, for example, describes the story's ability to "switch tracks" in his mind, such that he becomes "a child again listening to an elder." In other words, the cultural codes embedded in this particular recording have a transformative power that can connect a Cherokee listener to the storyteller, Will West Long, across "time and...death itself."

It is important to note, too, that Tom observes these powers adhere not just to the original act of storytelling but "even in a recording, disconnected from the actual person." This, I would argue, is an example of what might be termed the cultural codes of the digital recording that reveal the unique properties of Cherokee storytelling. The first shift, activated by the cultural codes embedded in the story, is to transform Tom from an academic linguist into a young boy sitting on his grandfather's porch in Oklahoma, listening to the elders speak in the high oratorical style of formal Cherokee. The next shift is even more profound, as Tom explains in this next passage:

The manner in which [Will West Long] spoke was an older form of addressing people....It is a very melodic way of speaking....We learned or know in the Cherokee language how that kind of information is best received....After all, we 
practiced this for millennia upon millennia....It is a validation of the great oratorical skill of our people. This is tantamount to saying we know the correct way...It's the way it's supposed to be done....And I think that maybe we could use that [recording] for our children to listen to, for the children in the immersion school to listen to, so that they get a model of what it is that they're trying to accomplish. [Belt 2010]

Interestingly, Tom discusses the story not in terms of the transcript or translation, but rather on the "melodic way of speaking" that constitutes the way "that kind of information is best received." It is telling, I think, that Tom never explains what exactly that "information" is. I suspect this is due to traditional protocols that stipulate this kind of information is not meant to be shared with non-Native people. While respecting those traditional protocols, Tom nevertheless demonstrates how the oratorical rhythms of the story's performance connect the listener back "millennia upon millennia" and thereby validate the story as worthy of being brought back to the community.

These kinds of things can be absolutely helpful in transmitting not just the sounds and not just the academic and scholastic nuances of the language... but to actually pass into another generation what it means to speak that language and to model how to think. Well, in this case then, the bottom line would be to model how to be [Cherokee]. [Belt 2010]

The challenge for non-Native academics, curators, and archivists is to learn to respect "the correct way...the way it's supposed to be done" in order for Digital Knowledge Sharing to be most effective. More prosaically, we need to acknowledge and respect that both partners have fully developed protocols. Part of this understanding is the realization that non-Native archivists and scholars will never fully understand "the correct way" (Belt 2010) in the manner of a fluent speaker and traditional knowledge keeper like Tom Belt, nor should we. Recognizing the difference between archival and traditional Cherokee knowledge systems, while still respecting the validity of each, demonstrates how cultural and archival protocols can work together.

If it's done properly, I think that [the APS] will be serving its purpose as stewards of indigenous heritage. Rather than just housing data and housing artifacts, the APS could now begin to house the very kinetic energy that is the soul of our lives and together we can create things with it. And wouldn't it be a wonderful thing for this institution to help out in this way. I think it would give them a chance to be an intrinsic part of keeping life going as opposed to just documenting death. [Belt 2010]

This, to my mind, is how a successful partnership with the Eastern Band of Cherokee Indians began in "the correct way." The APS, for its part, had to confront the fact that the Jeffersonian legacy was a form of "documenting death." And once we accepted this, Tom Belt was then able to share his knowledge of the "kinetic energy that is the soul of our lives" so that "together we can create" a meaningful partnership that would allow the digital materials to become "an intrinsic part of keeping life going." 


\section{When Stories Return Home}

Having selected, with Tom Belt's guidance, the proper recording to present to EBCI elders as a gift, we were now prepared for the return. I delivered the "Story of Long Life and Going to Heaven" in person to representatives of the Kituwah Preservation and Education Program (KPEP), managed by Renissa Walker, and the institutional home of T.J. Holland, Cultural Resource manager for the Eastern Band. T.J. and I have been friends for many years, so I usually just follow him around when I go to visit, trusting that he will let me know when to speak and when to remain silent. We began this trip by going to the KPEP total immersion elementary school, run by the tribe, which currently serves children ages seven months to seven years (another grade will be added onto the school each year, such that it will eventually go from preschool to twelfth grade). We began by presenting the $\mathrm{CD}$, with recordings made by Cherokee elders and anthropologists between 1935-1965, to Bo Lawson, the curriculum development specialist, who assured us that the students would be listening to the stories and songs by the end of the week.

As those who work with indigenous communities know all too well, word travels remarkably fast on the reservation. The next morning, T.J. explained that we were going back to the KPEP school for a special session of the Cherokee Speakers Consortium, a group of highly respected elders who had already listened to the recordings and had some questions they wanted answered. Part of T.J.'s job is to shield these elders from outside researchers, so I waited patiently in the parking lot, admiring the mist hanging over the Smoky Mountains. A few minutes later, T.J. reappeared. "They want to talk to you."

When I entered the room, there was a chair in the middle of a circle of elders. They introduced themselves and, although I had never met any of them other than Tom, I recognized many of the names from my research on the removal period, one hundred and eighty years earlier. And so it was both an honor and more than a little terrifying to take my seat in such distinguished company. Within a circle like this, one is acutely aware of a very different kind of intellectual hierarchy. I quickly abandoned my APS title of "subject expert," and listened as carefully as I possibly could. Tom and T.J. graciously explained the APS was deeply committed both to making the recently digitized material available to the community for cultural revitalization and to working with the elders to protect culturally sensitive materials from unauthorized dissemination. One of the elders leaned over and whispered in my ear. "The first voice on that $\mathrm{CD}$ is my maternal grandfather [Will West Long]. The next voice is my paternal grandfather. Don't worry. We'll help you."

\section{Notes}

1. The style of writing in this article is meant to reflect the values of respect and equality that it espouses. The history of the APS will be discussed as an "origin story," implicitly validating this rubric as being equally applicable to tribal histories and the history of the Founding Fathers. I have made a concerted effort to balance the quotes of scholars with quotes from traditional knowledge keepers that come from my interactions with these "community-based scholars." 
Following the example of Keith Basso and others who have worked closely with elders, I refer to them by their first name because to call Larry Aitken "Mr. Aitken" seems disrespectful since it imposes a western convention where none is needed.

2. To the best of my knowledge, the first major repatriation project undertaken by an archive was the Federal Cylinder Project, undertaken by the Folklife Center at the Library of Congress in 1979. Although the cylinders were on cassettes rather than digitized, it is the model on which digital repatriation was built for many (Gray 1991, 32-35). Since that time, there have been important case studies (Christen 2006, 56-60; Christen 2011, 185-201; Leopold 2013, 85-104). Perhaps the finest example of a more comprehensive study is a special issue of Museum Anthropology Review, entitled "After the Return" (Bell, Christen, and Turin 2013).

3. The most memorable instance of a tribal member wanting the original back was a Tuscarora elder asking for a letter her mother had sent to Anthony F. C. Wallace. She was, much to our mutual sadness, denied the request.

4. The cataloguing system at the APS is an example of how the epistemology of what we are calling colonialism is deeply embedded and difficult to change. My work here follows that of Jennifer O'Neal's ““'The Right to Know': Decolonizing Native American Archives” (O'Neal 2015). At the APS, for example, almost all of the collections bear the names of the white scholar who collected the information. In virtually every instance, as we will see, the scholar would not have been able to collect the vocabularies, ethnographies, or audio recordings without the cooperation of traditional knowledge keepers.

The APS is currently attempting to change this colonial legacy with the help of an NEH Preservation and Access grant to update the Native American Subject Guide. The Guide will include the names of indigenous knowledge keepers left out of the previous Guide. The plan is also to change the interface so that instead of an empty rectangle serving as the point of entry, researchers will see a spatio-temporal map with the indigenous communities marked and linked to the new subject guide, which lists the materials from each community. This land-based interface is also intended to more accurately reflect the importance of land in indigenous worldviews (Brooks 2008, xix-50).

5. The Penobscot elder Watie Akins is an exemplary instance of a community-based scholar who reconstructed and recreated Frank Speck's recordings of Penobscot songs to create two cds, For the Grandchildren and Greeting My Relations, that are now being used in Maine public school curriculum.

6. I especially want to thank Larry Aitken of the Leech Lake Ojibwe Band; Tom Belt from the Eastern Band of Cherokee Indians; Watie Akins an elder from the Penobscot Nation; Wendy Bissell and Chief Leo Henry of the Tuscarora Nation; and Anthony F. C. Wallace, a non-Native scholar who earned the title of traditional knowledge keeper through decades of working with the Tuscarora Nation.

7. About Us, accessed September 29, 2016, http://www.pimachiowinaki.org/about-us. 
8. Much of the Maureen Matthews collection is available on-line through the APS Digital Library, accessed September 29, 2016, http://diglib.amphilsoc.org/islandora/search/Maureen\%20Matthews?type=dismax.

9. See, for example, http://diglib.amphilsoc.org/islandora/object/graphics\%3A6610

10. Will West Long, "Story of Long Life and Going to Heaven," audio: 4983. This is the abbreviated record found on http://diglib.amphilsoc.org/islandora/search/Will\%20west\%20long?type=dismax (accessed September 29, 2016). Brian Carpenter, CNAIR's Senior Archivist, should be credited as doing the cataloguing for all three thousand and more hours of the digitization of the APS Native American audio collection.

\section{References Cited}

Aitken, Larry. 2007. Weweni: Be Careful. Videography by David McDonald. Interviewed by Timothy B. Powell. DMcD Productions.

American Philosophical Society. "Frank Siebert Finding Aid," accessed October 3, 2015, http://tinyurl.com/oxnvaq7.

Anderson, Jane. 2005. “Access and Control of Indigenous Knowledge in Libraries and Archives: Ownership and Future Use." Correcting Course: Rebalancing Copyright for Libraries in the National and International Area, American Library Association, The MacArthur Foundation, and Columbia University. New York: American Library Association and the MacArthur Foundation.

- 2006. "Indigenous Knowledge, Intellectual Property, Libraries and Archives: Crises of Access, Control and Future Utility." In Australian Indigenous Knowledge and Libraries, edited by Martin Nakata and Marcia Langton, 1-36. Sydney: UTSePress.

Atalay, Sonya. 2012. Community-Based Archaeology: Research With, By, and For Indigenous and Local Communities. Berkeley: University of California Press.

Barbeau, Marius. 1952. "Charles A. Cooke, Mohawk Scholar." Proceedings of the American Philosophical Society 96(4):424-426.

Barnhardt, Ray, and Angayuqaq Oscar Kawagley. 2008. "Indigenous Knowledge Systems and Education." Yearbook of the National Society for the Study of Education 107(1):223-241. https://doi.org/10.1111/j.1744-7984.2008.00144.x

Basso, Keith H. 1996. Wisdom Sits in Places: Landscape and Language among the Western Apache. Albuquerque: University of New Mexico Press.

Battiste, Marie. 2002. Indigenous Knowledge and Pedagogy in First Nations Education: A 
Literature Review with Recommendations. Ottawa: Apamuwek Institute.

Becvar, Katherine, and Ramesh Srinivasan. 2009. "Indigenous Knowledge and Culturally Responsive Methods in Information Research.” The Library 79(4):421-441. https://doi.org/10.1086/605382

Bell, Joshua A., Kimberly Christen, and Mark Turin. 2013. "Introduction: After the Return." Museum Anthropology Review 7(1-2):1-21.

Belt, Thomas. 2010. "Commentary on Will West Long 'Long Life and Going to Heaven." Manuscript. American Philosophical Society.

2010 Personal correspondence, May 10, 2010.

Boas, Franz and George Hunt. 1897. The Social Organization and the Secret Societies of the Kwakiutl Indians. Report of US National Museum. Washington: Government Printing Office.

Brooks, Lisa. 2008. The Common Pot: The Recovery of Native Space in the Northeast. Minneapolis: University of Minnesota Press.

Bruchac, Margaret. Forthcoming. Consorting with Savages: Indigenous Informants and American Anthropologists. Tucson: University of Arizona Press.

—. 2005. "Earthshapers and Placemakers: Algonikian Indian Stories and the Landscape." In Indigenous Archaeologies: Decolonizing Theory and Practice, edited by Claire Smith and H. Martin Wobst, 56-80. New York: Routledge.

Christen, Kimberly 2011. "Opening Archives: Respectful Repatriation." The American Archivist 74(1):185-210. https://doi.org/10.17723/aarc.74.1.4233nv6nv6428521

—. 2006. "Ara Irititja: Protecting the Past, Accessing the Future-Indigenous Memories in the Digital Age." Museum Anthropology 59(1):56-60.

Clifford, James. 1997. Routes: Travel and Translation in the Late Twentieth Century. Cambridge: Harvard University Press.

- 2004."Traditional Futures.” In Questions of Tradition, edited by Mark Phillips and Gordon J. Schochet, 152-168. Toronto: University of Toronto Press.

Cohen, Patricia. "Indian Tribes Go in Search of Their Lost Languages." The New York Times, April 5, 2010. Accessed September 29, 2016. http://www.nytimes.com/2010/04/06/books/06language.html? r=0

Collinson, Peter. 1763.“Letter to Benjamin Franklin.” September 9, 1763. Benjamin Franklin Papers. American Philosophical Society. 
Cushman, Ellen. 2013. "Wampum, Sequoyan, and Story: Decolonizing the Digital Archive." College English 76(2):115-132.

Darnell, Regna. 1998. And Along Came Boas: Continuity and Revolution in Americanist Anthropology. Philadelphia: John Benjamins Publishing. https://doi.org/10.1075/sihols.86

- 2001. Invisible Genealogies: A History of Americanist Anthropology. Lincoln: University of Nebraska Press.

Evers, Larry and Barre Toelken. 2001. Native American Oral Traditions: Collaborations and Interpretations. Logan: Utah State University Press.

Freeman, John and Murphy Smith. 1966. "Introduction." In Guide to Manuscripts Relating to the American Philosophical Society. Philadelphia: American Philosophical Society. https://doi.org/10.1111/j.1540-4781.1966.tb01845.x

Ginsberg, Faye. 1994. "Embedded Aesthetics: Creating a Discursive Space for Indigenous Media." Cultural Anthropology 9(3):365-382. https://doi.org/10.1525/can.1994.9.3.02a00080

Grant-Costa, Paul, Tobias Glazaand, and Michael Sletcher. 2012. "The Common Pot: Editing Native American Materials." The Annual of the Association for Documentary Editing $33: 1-18$.

Gray, Judith. 1991. "The Songs Come Home - The Federal Cylinder Project.” CRM 14(5):3235.

Harrison, K. David. 2007. When Languages Die: The Extinction of the World's Languages and the Erosion of Human Knowledge. New York: Oxford University Press. https://doi.org/10.1093/acprof:oso/9780195181920.001.0001

Hirtle, Peter B., Emily Hudson, and Andrew T. Kenyon. 2009. Copyright and Cultural Institutions: Guidelines for Digitization. Ithaca: Cornell University Library.

Jackson, Jason Baird. 2000. "Ethnography and Ethnographers in Museum-Community Partnerships.” Practicing Anthropology 22(4):29-32. http://hdl.handle.net/2022/3203

Jefferson, Thomas. 1791. "Vocabulary of the Unquachog Indians." American Philosophical Society Historical and Literary Committee, American Indian Vocabulary Collection. Accessed October 3, 2015 http://diglib.amphilsoc.org/islandora/search/dc.title\%3A\%28Unquachog\%29. 1999. Notes on the State of Virginia. New York: Penguin. 
Justice, Daniel Heath. 2006. Our Fire Survives the Storm: A Cherokee Literary History. Minneapolis: University of Minnesota Press.

Kalter, Susan. 2006. Benjamin Franklin, Pennsylvania, and the First Nations: The Treaties of 1736-62. Champaign, IL: University of Illinois Press.

Kelty, Christopher, Michael, M.J. Fischer, Alex "Rex" Golub, Jason Baird Jackson, Kimberly Christen, Michael F. Brown, and Tom Boellstorff. 2008. "Anthropology of/in Circulation: The Future of Open Access and Scholarly Societies." Cultural Anthropology 23(3):559-588. https://doi.org/10.1111/j.1548-1360.2008.00018.x

Kovach, Margaret. 2009. Indigenous Methodologies: Characteristics, Conversations, and Contexts. Toronto: University of Toronto Press.

Leopold, Robert. 2013. "Articulating Culturally Sensitive Knowledge Online: A Cherokee Case Study." Museum Anthropology Review 7(1-2):85-104.

Lingelbach, William E. 1953. "The American Philosophical Society Library from 1942 to 1952 with a Survey of its Historical Background." Proceedings of the American Philosophical Society 97(5):471-492.

McMullen, Ann. 2008. "The Currency of Consultation and Collaboration." Museum Anthropology Review 2(2):54-87.

O’Neal, Jennifer R. 2014. "Respect, Recognition, and Reciprocity: The Protocols for Native American Archival Materials." In Identity Palimpsests: Archiving Ethnicity in the US and Canada, edited by Dominique Daniel and Amalia Levi, 125-142. Sacramento: Litwin Press.

—. 2015. “"The Right to Know': Decolonizing Native American Archives.” Journal of Western Archives 6(1): 1-17.

Powell, Timothy B. 2016. "Steering a Course Set by Thomas Jefferson: New Developments in the Native American Collections at the American Philosophical Society." Proceedings of the American Philosophical Society 159(3):282-295.

—. 2015a. "Honoring the Past, Enlivening the Future: The New Center for Native American and Indigenous Research.” American Philosophical Society Newsletter. Fall 2015.

—. 2015b. "American Philosophical Society Protocols for the Treatment of Indigenous Materials.” American Philosophical Society Proceedings 158(4):411-420.

Powell, Timothy B. (author), William Weems (web design), Freeman Owle (storytelling), and Jeffrey Moro (conversion to web resource). 2007. "Native/American Digital Storytelling: Situating the Cherokee Oral Tradition within American Literary History," Literature 
Compass 4(1):1-23. Accessed September 29, 2016, http://lbrooks.people.amherst.edu/nadigitalstorytelling/.

Reddy, Sita, and D. A. Sonneborn. 2013. "Sound Returns: Toward Ethical 'Best Practices' at Smithsonian Folkways Recordings.” Museum Anthropology Review 7(1-2):127-139.

Roy, Loriene, and Mark Chistal. 2000. "Creating a Virtual tour of the American Indian." NAAAS Conference Proceedings: 2086-2103. Scarborough: Scarborough National Association of African American Studies.

Shankar, Guha, and Cordeila Hooee. 2013. "Zuni Cultural Heritage Materials in the American Folklife Center: The Potential of Return.” Museum Anthropology Review 7(1-2): 74-84.

Smith, Benjamin Barton. 1792. Smith, Benjamin Barton. "Letter to Thomas Pennant,” July 12. Benjamin Smith Barton Papers, American Philosophical Society.

Smith, Claire, and H. Martin Wobst. 2005. Indigenous Archaeologies: Decolonising Theory and Practice. New York: Routledge.

Speck, Frank G., Leonard Broom, and Will West Long. 1951. Cherokee Dance and Drama. Norman: University of Oklahoma Press.

Swan, Daniel C. and Michael Paul Jordan. 2015. "Contingent Collaborations: Patterns of Reciprocity in Museum-Community Partnerships.” Journal of Folklore Research 52(1):39-84. https://doi.org/10.2979/jfolkrese.52.1.39

Tierney, William G. 1992. Official Encouragement, Institutional Discouragement: Minorities in Academe-The Native American Experience. Greenwich, CT: Ablex Publishing Corporation.

Trouillot, Michel-Rolph. 2003. Global Transformations: Anthropology and the Modern World. New York: Palgrave Macmillan. https://doi.org/10.1007/978-1-137-04144-9

Tuhiwai Smith, Linda. 2004. Decolonizing Methodologies: Research and Indigenous Peoples. New York: Palgrave.

Wallace, Anthony F.C. 1999. Jefferson and the Indians: The Tragic Fate of the First Americans. Cambridge: Harvard University Press.

Watkins, Joe. 2001. Indigenous Archaeology: American Indian Values and Scientific Practice. Walnut Creek, CA: AltaMira.

Weiner, Annette B. 1992. Inalienable Possessions: The Paradox of Keeping-While Giving. University of California Press.

Witthoft, John. 1948. "Will West Long, Cherokee Informant.” American Anthropologist 50(2): 


\section{5-359. https://doi.org/10.1525/aa.1948.50.2.02a00250}

Timothy B. Powell is the Director of the American Philosophical Society's Center for Native American and Indigenous Research. He is also a Senior Lecturer in the Department of Religious Studies at the University of Pennsylvania and a Consulting Scholar at the Penn Museum. Powell is the author of several works, including a forthcoming contribution to Franz Boas: Ethnographer, Theorist, Activist, Public Intellectual (edited by Regna Darnell; Lincoln: University of Nebraska Press).

http://dx.doi.org/10.14434/10.14434/mar.v10i2.20268 